\title{
JUURNAL.RU
}

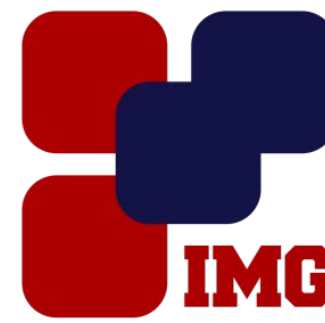

IYANOY
MaNAGEMENT
GROUP

Егоров С.А. ФГБОУ ВО МГТУ «СТАНКИН» Москва, Россия

doi: 10.18411/lj-31-01-2017-4-05

idsp 000001:lj-31-01-2017-4-05

\section{Анализ методик наномодифицирования полимерных композиционных материалов}

Для разработки новых конструкционных материалов с выдающимися свойствами все чаще применяются углеродные нанотрубки и нановолокна. Подобные инновационные технологии находят все большее применение как в оборонной (ракето- и самолетостроении), автомобильной промышленности, медицине, так и в повседневной жизни [1]. Процесс получения подобных материалов осложнен природой углеродных нанотрубок. При производстве углеродных нанотрубок получаются механически запутанные структуры, которые самопроизвольно собираются в агрегаты и/или просто переплетаются в процессе роста. Агрегированные наночастицы нуждаются в рассеивании в жидких средах для дальнейшего их использования.

Задача рассеивания углеродных нанотрубок с целью разбиения пучков и агрегатов рассматривается многими авторами. Предложено несколько различных путей решения задачи диспергирования нанотрубок: размалывание, ультразвуковое воздействие, функционализация поверхности и использование поверхностно активных агентов. Тот или иной метод выбирают, учитывая дальнейшее применение полученной суспензии. Чаще всего используется ультразвуковое воздействие в сочетании с поверхностно активными веществами, которые препятствуют обратной реагрегации пучков.

Рассмотрим отдельно различные методы механического диспергирования УНТ. Известен способ диспергирования упрочнителя в синтетической смоле, в котором частицы упрочнителя и смолу помещают в сосуд и перемешивают их с помощью установленного в сосуде лопастно-шнекового механизма[2]. Недостатком способа в случае его применения для диспергирования наночастиц, в смеси их со смолой является неравномерность распределения наночастиц в смоле, которая может быть связана с недостаточно интенсивным механическим перемешиванием наночастиц со смолой, а также с наличием зазоров между 
рабочими поверхностями лопастно-шнекового механизма и поверхностями стенки сосуда, размеры которых значительно превышают размеры наночастиц.

Известен способ диспергирования наночастиц в смоле с использованием механических или ультразвуковых колебании, при котором жидкую смесь нагревают перед диспергированием или во время диспергирования и охлаждают после диспергирования.Недостатком данного способа являются отсутствие охлаждения жидкой смеси наночастиц со смолой во время диспергирования, вследствие чего нагрев смеси во время диспергирования может приводить к изменению структуры молекул смолы, что приводит к уменьшению прочности.

Известен способ диспергированиянаночастиц в эпоксидной смоле, в котором наночастицы предварительно диспергируют в растворителе с применением ультразвуковых колебаний, полученную дисперсию смешивают со смолой, а затем из полученной смеси испаряют растворитель.

Данный способ позволяет получить при диспергировании равномерное распределение наночастиц в смоле. Однако у него имеются недостатки:

- трудно обеспечить полное удаление растворителя из смеси его со смолой и наночастицами, некоторое его количество остается и способствует образованию пор;

- операция предварительного диспергирования наночастиц в растворителе и операция удаления растворителя усложняют и удорожают способ.

Существует способ диспергирования наночастиц в жидкой эпоксидной смоле, в котором наночастицы в виде углеродных нанотрубок смешивают с эпоксидной смолой и подвергают смесь ультразвуковым колебаниям в течение 5 часов.Этот способ позволяет получить при диспергировании равномерное распределение наночастиц в смоле. Однако у него имеются недостатки: большая продолжительность процесса диспергирования и отсутствие контроля температуры диспергируемой смеси. Согласно проведенным экспериментам и наноизмерениям при большой длительности диспергирования может значительно (более чем в 1000 раз) уменьшаться длина нанотрубок, что должно уменьшать и когезионную, и адгезионную составляющие прочности.

Для диспергирования УНТ в полимерных композиционных материалах наиболее рационально применять ультразвуковую обработку.

$\mathrm{B}$ результате наномодифицирования углеродными нанотрубками существенно повышаются физико-механические свойства композитов. В работе [3] выявлена зависимость изменения механической прочности от технологии приготовления связующего при модификации УНТ.

Наибольший рост механических показателей установлен для следующих типов модификаторов:

- концентрат УНТ (введение в изо-МТГФА при помощи механического смешения) - при содержании 0,05\%(от массы отвердителя) прочность возрастала с 127,9 МПа до 145 МПа; 
- концентрат УНТ (введение в эпоксидную смолу при помощи механического смешения) - при содержании 0,003-0,007\% (от массы эпоксидной смолы) прочность возрастала с 127,9 МПа до 145 Мпа (рис.1).

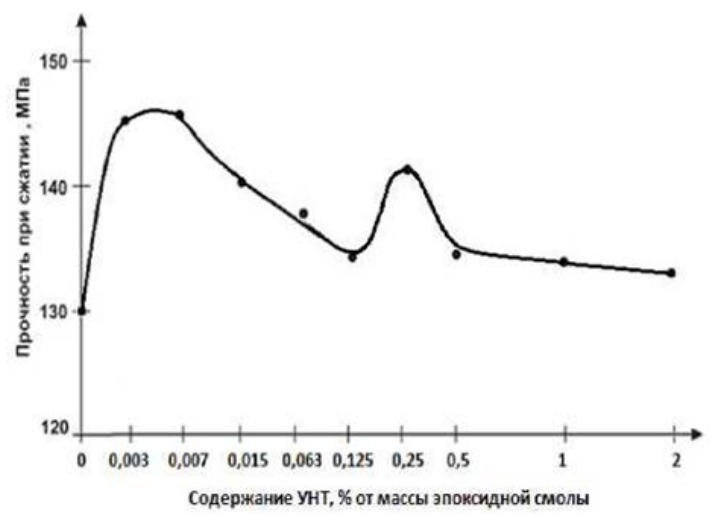

Рис.1. Зависимость прочности при сжатии эпоксидного композита от содержания УНТ

Наиболее оптимальной технологией (с позиций достижения максимальной прочности) является технология, включающая введение концентрата УНТ в отвердитель и в эпоксидную смолу и механическое смешение всех компонентов.

Установлено [4], что композиционные материалы, включающие в состав УНМ, демонстрируют интересные физико-механические свойства уже при малых концентрацияхнаполнителя (до 1 \% масс.), что выгодно отличает материалы этого типа от «традиционных» композиционных материалов. Однако, несмотря на малое содержание наполнителя, у таких систем наблюдается увеличение электропроводности, повышение прочности, улучшение ряда других свойств. Установлено, что введение в качестве наполнителей УНМ обработанных азотной кислотой приводит к повышению разрушающего напряжения при изгибе на $28 \%$, при сжатии на $38 \%$.

В некоторых работах $[5,6]$ исследовано влияние низких концентраций ОУНТ на свойства полимеров и показано, что существенного изменения физикомеханических характеристик можно добиться путем введения функционализированных углеродных нанотрубок (ф-УНТ) в количествах $0,03-$ 0,06 мас. \%. Понятно, что при столь малых концентрациях фУНТаддитивностью свойств составляющих нанокомпозита уже нельзя объяснить увеличения механических свойств. В [7] отмечено, что введение фУНТ в концентрациях менее $0,1 \%$ приводит к существенному изменению структуры термопластичных и термореактивных полимерных матриц.

В работе [8] излагается новый подход в получении нанокомпозитов гранульный. Под гранульным подходом понимается использование гранулированных МУНТ определенного размера и структуры. В первую очередь гранулы должны быть достаточно дисперсные и хорошо пропитываться смолой. Такие гранулы (рис.2) не идентичны исходным, полученным при производстве УHT. 


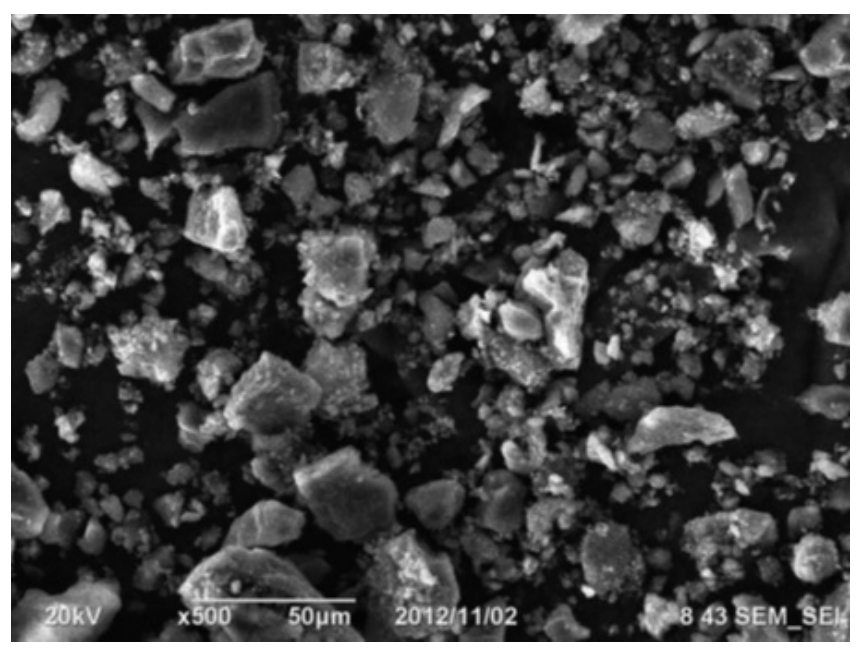

Рис.2. Внешний вид гранул МУНТ

При малых концентрациях гранул МУНТ, они образуют локальные включения, окруженные связующим и не формируют пространственную сетку сопряженных узлов. Как и любые локальные включения гранулы МУНТ в этом случае не оказывают влияния на всю матрицу. То, что нет заметного снижения прочностных показателей, указывает на хорошую пропитку гранул смолой. В этом случае отсутствует отрицательный фактор концентрации напряжения в области локального включения. С увеличением концентрации гранул МУНТ в первую очередь наблюдается резкий рост модулей упругости. При концентрации гранул МУНТ 15 масс.\% модули упругости на растяжение и на изгиб выросли со-ответственно в 4,17 и 1,73 раза. При этой концентрации выросли и прочностные показатели. Прочность на изгиб увеличилась на 20,3\%, а на растяжение почти на $6 \%$. С дальнейшим увеличением концентрации гранул МУНТ понижаются величины модулей упругости и прочностные данные.

Гранульный способ получения нанокомпозитов не требует какого-то специфического оборудования помимо применяемого в производстве композиционных материалов, особых требований к технологам и рабочим на производстве. Он легко масштабируется. Совершенствование технологии синтеза МУНТ несомненно приведет в будущем к резкому снижению их стоимости и этот фактор является определяющим для промышленного масштабирования данной технологии.

По результатам проведенной работы можно сделать следующие выводы:

- УНТ склонны образовывать агломераты, препятствующие их равномерному распределению в матрице и тем самым не позволяющие достичь желаемой эффективности при модификации полимера. Поэтому их необходимо деагломерировать;

- Деагломерирование можно проводить различными методами, но одним из самых эффективных является метод ультразвуковой обработки;

- Для диспергирования УНТ в связующем при помощи ультразвукового воздействия используют различные методики, 
отличающиеся этапом введения УНТ (в растворитель, отвердитель и т.д.), временем обработки и др.;

- Улучшение прочностных свойств существенно уже при малых концентрациях наполнителя (до 1 \% масс.), что выгодно отличает материалы этого типа от «традиционных» композиционных материалов;

- Существует перспективный гранульный метод получения нанокомпозитов, имеющий ряд важных преимуществ, по сравнению с традиционными методами. Несомненно, совершенствование технологий синтеза МУНТ приведет к снижению их цены и более широкому распространению метода.

\section{Литература}

1. Н.А. Федосова, П.П. Файков, К.С. Зараменских, Н.А. Попова, Е.В. Жариков, Э.М. Кольцова. Разработка дисперсионной среды на основе углеродных нанотрубок для армирования керамических материалов.

2. Титов Сергей Анатольевич, Ткачев Алексей Григорьевич, Аниховская Любовь Ивановна, Слепов Севастьян Карпович. Изобретение «Способ диспергирования наночастиц в эпоксидной смоле» (RU 2500706)

3. В. Г. Хозин, Е. С. Зыкова. Модифицирование эпоксидных связующих наночастицами для полимеркомпозитной арматуры.

4. Б. К. Динистанова, Ж. Ж. Сулубеков, А. Ж. Жаленова, 3. А. Мансуров. Физико химические основы получения полимер-композиционных материалов на основе эпоксидной смолы.

5. MoniruzzmanM., Fangming Du, Romero N., Winey K.I. Increased flexural modulus and strength in SWNT/epoxy composites by a new fabrication method // Polymer. 2006. V. 47. P. 293-298

6. Long Xie, Feng Xu, Feng Qiu et al. Single-Walled Carbon Nanotubes Functionalized with High Bonding Density of Polymer Layers and Enhanced Mechanical Properties of Composites // Macromolecules. 2007. V. 40. N 9. P. 3296- 3305.

7. Грачев В.П., Акатенков Р.В., Алексашин В.Н. и др. Повышение свойств эпоксидных полимеров малыми добавками функционализированных углеродных наночастиц / Rusnanotech 08: Сб. тез. докл. I Межд. форум по нанотехнологиям (Москва, 3-5 декабря 2008 г.). С. 410-412.

8. Крючков В.А., Крючков М.В., Выморков Н.В., Портнова Я.М., Бушанский Н.В., Бушанский С.Н. Получение полимерных нанокомпозитов с использованием гранулированных многослойных углеродных нанотрубок 